JOURNAL of

MAINE MEDICAL CENTER Journal of Maine Medical Center

\title{
Perceptions of Maine Health Care Providers on Youth Tobacco Use and Prevention Efforts
}

\author{
Titilola Balogun \\ University of New England
}

Et al.

Follow this and additional works at: https://knowledgeconnection.mainehealth.org/jmmc

Part of the Community Health and Preventive Medicine Commons

\section{Recommended Citation}

Balogun, Titilola; Soma, Toho; and O'Brien, Liam (2021) "Perceptions of Maine Health Care Providers on Youth Tobacco Use and Prevention Efforts," Journal of Maine Medical Center. Vol. 3 : Iss. 2 , Article 3. Available at: https://knowledgeconnection.mainehealth.org/jmmc/vol3/iss2/3 https://doi.org/10.46804/ 2641-2225.1076

The views and thoughts expressed in this manuscript belong solely to the author[s] and do not reflect the opinions of the Journal of Maine Medical Center or MaineHealth.

This Original Research is brought to you for free and open access by Maine Medical Center Department of Medical Education. It has been accepted for inclusion in the Journal of Maine Medical Center by an authorized editor of the MaineHealth Knowledge Connection. For more information, please contact Dina McKelvy mckeld1@mmc.org.

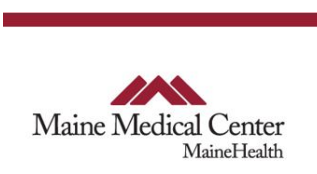




\section{Perceptions of Maine Health Care Providers on Youth Tobacco Use and Prevention Efforts}

\section{Authors}

Titilola Balogun, Toho Soma, and Liam O'Brien 


\title{
ORIGINAL RESEARCH
}

\section{Perceptions of Maine Health Care Providers on Youth Tobacco Use and Prevention Efforts}

\author{
Titilola Balogun, MBBS, MPH, DrPH, ${ }^{1}$ Toho Soma, MPH, MS, ${ }^{2}$ Liam O’Brien, $\mathrm{PhD}^{3}$ \\ ${ }^{1}$ Graduate Programs in Public Health, University of New England, Portland, ME, ${ }^{2}$ Center for Excellence in Public Health, \\ University of New England, Portland, ME, ${ }^{3}$ Department of Mathematics and Statistics, Colby College, Waterville, ME
}

\begin{abstract}
Introduction: Tobacco use causes preventable morbidity and mortality, and leads to high medical costs annually. In Maine, both cigarette and electronic cigarette (e-cigarette) use among high school students are higher than the national average. To what extent Maine health care providers are familiar with tobacco use prevention is unknown. We aimed to describe the knowledge, attitudes, and practices of Maine health care providers regarding youth tobacco use. We also determined what preventive services they provide, and measured their self-efficacy regarding screening and counseling for tobacco use.
\end{abstract}

Methods: $\quad$ In this cross-sectional study, health care providers were surveyed about their knowledge, attitudes, and
measured their self-efficacy and practices related to youth tobacco use. Logistic regression modeling
and chi-square tests were used to determine associations between variables.

Results: $\quad$ Providers with at least 10 years of experience had more self-efficacy to discuss cigarettes (OR, 3.4; 95\% $\mathrm{Cl}, 1.6-7.4 ; \mathrm{P}=.002)$ and chewing tobacco $(\mathrm{OR}, 3.1 ; 95 \% \mathrm{Cl}, 1.5-6.8 ; \mathrm{P}=.003)$, but not e-cigarettes $(\mathrm{OR}, 1.2 ; 95 \% \mathrm{Cl}, 0.6-2.5 ; \mathrm{P}=.6)$, with their patients. However, neither self-efficacy nor familiarity with prevention resources and policies impacted screening practices.

Discussion: Knowledge alone is not sufficient to cause behavioral change. However, the high self-efficacy expressed by providers indicates their willingness to adopt changes to their clinical practices, given adequate training.

Conclusions: There are knowledge and practice gaps in tobacco prevention efforts. Training health care providers and implementing tobacco screening practices will improve the quality of health services offered to Maine youth at clinic visits.

Keywords: $\quad$ tobacco use, adolescents, youth, health care providers

$\mathrm{n}$ the United States, tobacco use is a major cause of preventable morbidity and mortality that results in $\$ 170$ billion in medical costs every year. ${ }^{1}$ Between 2011 and 2019, use of cigarettes, cigars, and smokeless tobacco among youth declined steadily. ${ }^{2}$ However, the use of electronic cigarettes (e-cigarettes) increased. In 2019, 28\% of all high school students reported using e-cigarettes in the past 30 days. $^{3}$ The 2017 National Youth Tobacco Survey showed that among all high school students who currently use any form of tobacco, $47 \%$ used

Correspondence: Titilola Balogun, MBBS, MPH, DrPH

University of New England

716 Stevens Avenue

Portland, ME 04103

tbalogun@une.edu
2 or more products. The survey also showed that e-cigarettes were the most frequently used tobacco product by youth nationwide. ${ }^{3}$ The most common documented reasons for using e-cigarettes were the use of e-cigarettes by a family member or friend, the availability of pleasant flavors, and the perception that e-cigarettes are less harmful than "regular" cigarettes. ${ }^{4}$ Risk factors for starting tobacco use include issues related to self-image, peer and family influence, stress, online advertising of tobacco products in the media and movies, and other cultural factors. ${ }^{2}$

In Maine, information about health and healthrelated behaviors among high school students is collected every odd-numbered year using the Maine 
Integrated Youth Health Survey. ${ }^{5}$ Recent data from the survey show that current e-cigarette use among high school students almost doubled from $15 \%$ in 2017 to $29 \%$ in $2019 .{ }^{6}$ E-cigarette use was evenly distributed among public health districts. ${ }^{7}$

As is the case nationally, the prevalence of "regular" cigarette smoking among high school students in Maine is decreasing. Current cigarette use was $7 \%$ in 2019 compared to $9 \%$ in 2017 and $11 \%$ in $2015 .^{7-9}$ Although the rates for cigarette smoking are declining, both cigarette and e-cigarette use among Maine high school students are much higher than the national average..$^{2,10}$ In addition, current cigarette use is higher among Maine youth compared to other states in New England, except Vermont. ${ }^{10}$

According to the Surgeon General's report on smoking and health, almost $90 \%$ of adult smokers started smoking before 18 years old. Based on current trends, 1 in every 13 people who are currently children may die from a tobacco-related illness later in life. ${ }^{11}$ Tobacco use, including noncombustible products like chewing tobacco, leads to many complications, such as cancer, heart disease, low birth weight, preterm delivery, and chronic obstructive pulmonary disease. ${ }^{12,13}$ These complications call for strong efforts in primary and secondary prevention to minimize the burden and consequences of tobacco use.

The Committee on Substance Use and Prevention of the American Academy of Pediatrics (AAP) recommends that health care providers increase their capacity to screen for and manage substance use in pediatric patients. ${ }^{14}$ Additionally, in 2019, the US Preventive Services Task Force released updated recommendations on the benefits of primary care-related screening and counseling of pediatric and adolescent patients in preventing tobacco use among youth. ${ }^{15}$ To what extent health care providers in Maine are aware of or adhere to these policies is unknown. Given that studies have shown a protective relationship between information received from a health care provider and tobacco use among youth, ${ }^{16-18}$ health care providers across the state of Maine were surveyed to assess their knowledge, attitudes, and practices regarding youth tobacco use; determine what preventive services they provide; and measure their selfefficacy regarding screening and counseling for tobacco use.

\section{METHODS}

\section{Study design}

This cross-sectional study conducted an online survey of health care providers across Maine between February 2019 and November 2019. The study was deemed exempt by the University of New England's Institutional Review Board.

\section{Subject recruitment}

A survey link was sent via email to health care providers through their professional associations, including the Maine Chapter, AAP; Maine Nurse Practitioners Association; Maine Dental Association; Maine Dental Hygienists Association; and Maine Association of Physician Assistants. A contact person from each organization was identified, and these contacts shared the survey link with their members. The inclusion criteria were all health care providers in Maine who see patients aged 11 to 18 years.

We developed a 24-question survey to evaluate the knowledge, attitudes, self-efficacy, and practices of health care providers on youth tobacco use. The survey included multiple choice, Likert-scale, and open-ended questions. Details of the survey can be found in the supplementary materials.

\section{Data analysis}

Data were collected using REDCap and exported to Stata IC/15 software for analysis. ${ }^{19}$ Frequency tables and charts were generated. Logistic regression analyses were used to determine associations between predictor variables (geographical location, duration of practice) and outcome variables (familiarity with the magnitude of tobacco product use, familiarity with tobacco prevention resources, confidence to discuss tobacco use, confidence to screen for tobacco use, and confidence to offer counseling for tobacco use). Ordinal logistic regression analyses were used for responses with more than 2 levels (confidence to discuss e-cigarette use, confidence to discuss chewing tobacco, and confidence to discuss tobacco issues with parents).

Chi-square tests of association were also used to determine whether significant associations exist between binary categorical variables (availability of screening policies, availability of counseling policies). 
Dummy variables were created for the question "How familiar are you with the magnitude of combustible (regular) cigarette use among Maine youth between the ages of 11 and 18 years?" The options were recoded to a binary variable. The responses "Very familiar" and "Somewhat familiar" were recoded to "Familiar," while the responses "Somewhat unfamiliar" and "Unfamiliar" were recoded to "Unfamiliar." This recoding was also done with the e-cigarette version of the question. Geographical location was self-reported by health care providers and collapsed into binary variables such that "Urban" and "Neither urban nor rural" were recoded to "Urban" for bivariate logistic regression and chi-square analysis.

Frequency of screening for each variable of cigarettes, e-cigarettes, and chewing tobacco were also collapsed into binary variables. "Annually," "At every well-child visit," and "At every sick visit" were coded as "1." Also, "Never," "Rarely," "No particular frequency," and "Upon request by parent/ guardian" were coded as "0." Significance level was set at $P<.05$. All confidence intervals had a $95 \%$ confidence level.

\section{RESULTS}

Of 128 participants who took the survey, 14 were not health care providers and were excluded. Table 1 shows the demographic characteristics of study participants. More than $90 \%$ described themselves as female, and most described their geographical location as rural.

\section{Knowledge}

Most providers were familiar with the magnitude of cigarette and e-cigarette use among Maine youth. Providers were evenly split on their knowledge of age at which youth start smoking: $51 \%$ agreed and $49 \%$ disagreed that youth start smoking at age 12 years or younger. Also, 40\% agreed and $60 \%$ disagreed that youth started smoking at age 14 years or older. The survey also showed that $77 \%$ of participants agreed that 1 in 4 youth would try smoking a cigarette if their friend offered it to them. Also, $60 \%$ agreed that $16 \%$ of youth aged 14 years or older have used an e-cigarette. Among health care providers, $95 \%$ agreed that having a family member or friend who smokes is a risk factor for youth tobacco use. Their familiarity with the magnitude of use was $90 \%$ for e-cigarettes and $88 \%$ for cigarettes.
Table 1. Demographic Characteristics of Study Participants

\begin{tabular}{|c|c|}
\hline Characteristic & N (\%) \\
\hline $\begin{array}{l}\text { Age, y } \\
25-34 \\
35-44 \\
45-54 \\
55 \leq \\
\text { Prefer not to say }\end{array}$ & $\begin{array}{l}10(9) \\
35(31) \\
32(28) \\
36(32) \\
1(1)\end{array}$ \\
\hline $\begin{array}{l}\text { Sex } \\
\text { Female } \\
\text { Male } \\
\text { Prefer not to say }\end{array}$ & $\begin{array}{l}104(91) \\
8(7) \\
2(2)\end{array}$ \\
\hline $\begin{array}{l}\text { Duration of Practice, y } \\
<5 \\
5-9 \\
10-14 \\
15-20 \\
>20\end{array}$ & $\begin{array}{l}24(21) \\
18(16) \\
22(19) \\
19(17) \\
31(27)\end{array}$ \\
\hline $\begin{array}{l}\text { Geographical location } \\
\text { Rural } \\
\text { Urban } \\
\text { Neither urban nor rural }\end{array}$ & $\begin{array}{l}68(60) \\
24(21) \\
22(19)\end{array}$ \\
\hline $\begin{array}{l}\text { Job title } \\
\text { Nurse* } \\
\text { Nurse practitioner } \\
\text { Physician } \\
\text { Social worker } \\
\text { Counselor } \\
\text { Dental hygienist } \\
\text { Dentist } \\
\text { Clinical therapist } \\
\text { Physician assistant }\end{array}$ & $\begin{array}{l}40(36) \\
28(25) \\
14(13) \\
13(12) \\
11(10) \\
2(2) \\
2(2) \\
1(1) \\
1(1)\end{array}$ \\
\hline
\end{tabular}

${ }^{*}$ Includes school nurses and registered nurses

Comparing the geographical location of the health care provider, logistic regression modeling indicated that the odds that rural providers were familiar with regular cigarette use was 4.4 times higher than for urban providers $(95 \% \mathrm{Cl}, 1.3-15.1 ; P=.01)$. However, there was no significant difference in familiarity with e-cigarette use between urban and rural providers (OR, 1.89; 95\% Cl, 0.5-6.6; $P=.31)$. With respect to duration of practice, familiarity with the magnitude of cigarette or e-cigarette use did not differ significantly between providers with less than 10 years of experience and providers with 10 
years or more experience (Table 2). Awareness of existing policies or resources, and their distribution by practice duration, are shown in Figure 1.

Duration of practice was not significantly associated with knowledge of MaineHealth Center for Tobacco Independence, the Surgeon General's requirements, the AAP statement, or other prevention services and resources (Table 2). Also, familiarity with these resources was not associated with a greater frequency of screening for cigarettes (OR, 1.6; 95\% Cl, 0.7- 3.9; $P=.1$ ), e-cigarettes (OR, $2.1 ; 95 \% \mathrm{Cl}, 0.8-5.1 ; P=.3)$, or chewing tobacco (OR, 1.9; 95\% Cl, 0.7-5.0; $P=.3$ ).

Geographical location was not significantly associated with familiarity with MaineHealth Center for Tobacco Independence (OR, 1.4; 95\% Cl, $0.6-3.1 ; P=.43)$, the Surgeon General's advisory (OR, 0.7; 95\% Cl, 0.3-1.6; $P=.4$ ), the AAP policy on screening (OR, $0.89 ; 95 \% \mathrm{Cl}, 0.4-1.9 ; P=.8)$, or other tobacco prevention resources in Maine.

\section{Attitudes}

Attitudes toward various tobacco products differed (Table 3). Among providers, 99\% disagreed with the statement that chewing tobacco was safer than inhaled tobacco, 98\% disagreed that e-cigarettes are safer than regular cigarettes, and $95 \%$ disagreed that e-cigarettes could help youth stop smoking regular cigarettes. On who should counsel youth on tobacco use, most providers indicated parents (90\%), followed by physicians $(64 \%)$, school teachers $(46 \%)$, nurses $(40 \%)$, school counselors $(36 \%)$, nurse practitioners $(32 \%)$, dentists $(24 \%)$, social workers $(19 \%)$, and physician assistants $(14 \%)$. The results of the other measures for attitudes are presented in Table 3.

\section{Practice}

Only $29 \%$ of providers reported the existence of worksite policies on screening for use of cigarettes, e-cigarettes, or any tobacco by youth ages 11 to 18 years. And only $25 \%$ reported the existence of policies related to offering counseling on tobacco use to youth. There was no significant difference between rural and urban providers regarding the availability of screening $\left(X^{2}=1.28 ; P=.26\right)$ or counseling $\left(X^{2}=0.32 ; P=.57\right)$ policies. The results for the question "In the past 12 months, how often did you screen youth between the ages of 11 and 18 years for combustible (regular) cigarette use?" are presented in Table 3.

\section{Self-efficacy}

Most providers reported confidence in their ability to discuss tobacco use with patients aged between 11 and 18 years (Table 2). Using ordinal logistic regression, at least 10 years of practice was associated with confidence to discuss cigarette and chewing tobacco use, but not e-cigarette use, with patients (Table 2).

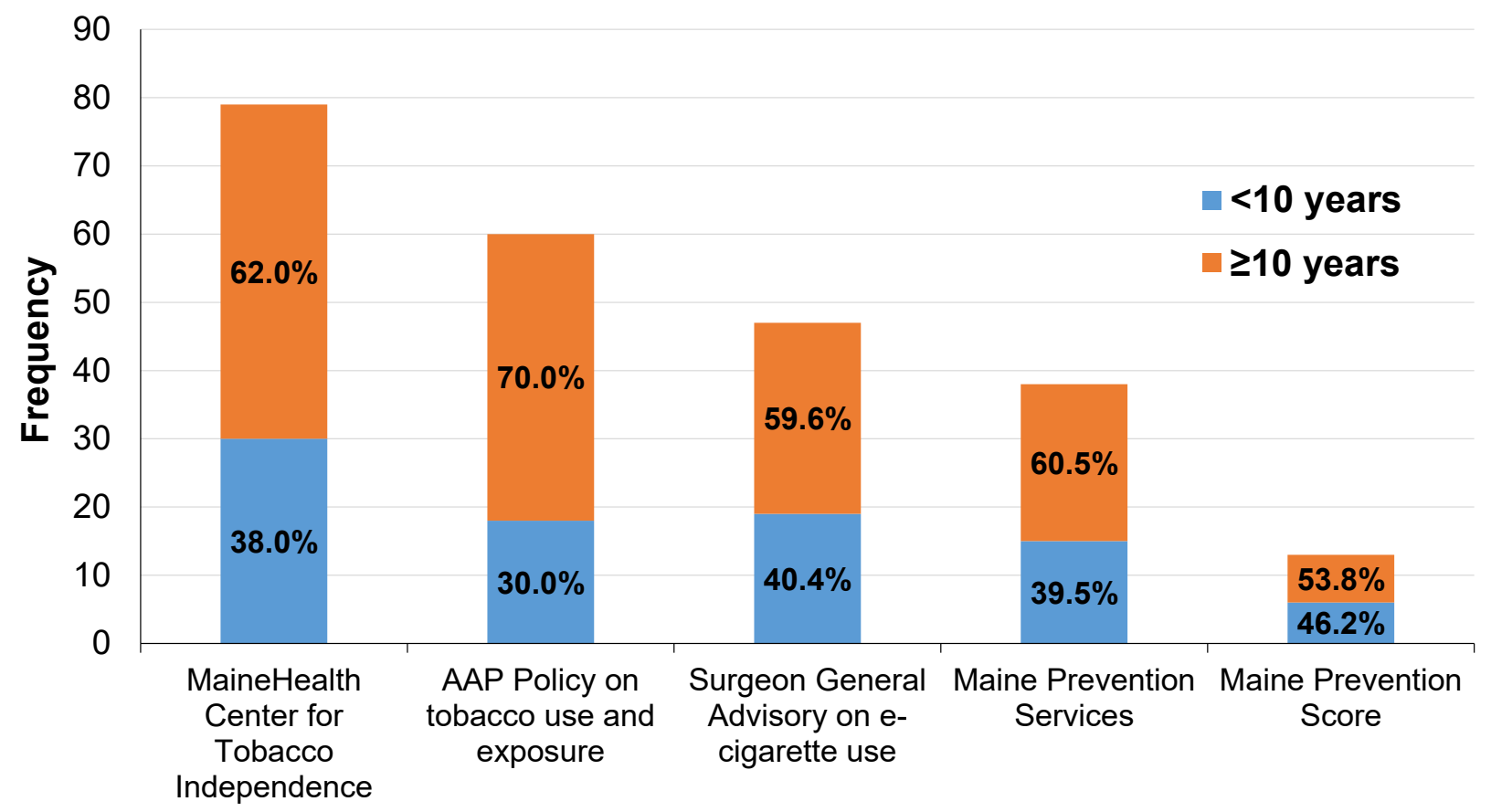

Figure 1. Maine Health Care Provider Familiarity with Tobacco Prevention Resources and Policies

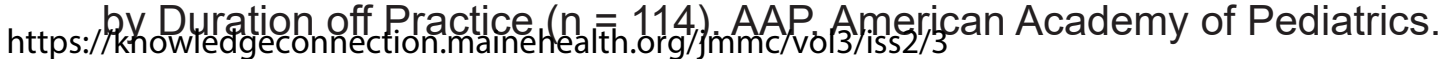




\section{DISCUSSION}

Health care providers at MaineHealth are knowledgeable about youth tobacco use. However, slightly more providers are aware of e-cigarette use compared to regular cigarette or chewing tobacco use. We attribute this greater awareness to the increased coverage of e-cigarettes in the media and across public health platforms in recent years. We asked providers what they thought about the age of onset of tobacco use, because knowing the age at which use starts is key to timing effective intervention efforts. The more knowledgeable health care providers and administrators are, the more likely they can proactively intervene at earlier ages. Overall, Maine providers know that youth start using tobacco products well before the age of 18 years. One reason for the rise in use of e-cigarettes by youth is the belief that they are safer than regular cigarettes. ${ }^{4}$ Because health care providers comprehend the magnitude of youth tobacco use and the risk of using tobacco products, they have a strong base on which to advise patients and their families. Interestingly, despite having more clinical experience, health care providers who have been in practice for at least 10 years are not more knowledgeable about the magnitude of tobacco use, nor are they more likely to express confidence in discussing e-cigarette use with patients. We posit that this finding is logical, particularly if providers have not received formal training in preventing e-cigarette use.

Another important finding is that many providers in our study were not knowledgeable about the existence of prevention policies and resources, with the exception of the MaineHealth Center for Tobacco Independence. Even among providers who were aware, their knowledge of national and local prevention resources was not significantly associated with their screening and counseling practices. The reason could be beyond their control and more within the scope of healthcare administrators and school superintendents who can develop and enforce policies. This possibility has implications for practice because adhering to existing policies by the Surgeon General, AAP, and other advocacy organizations should improve prevention efforts and health outcomes.

Althoughknowledgeinforms intervention, knowledge alone is not sufficient to drive behavioral or policy change. This notion was supported by our finding that knowledge of the magnitude of the problem, or of available tobacco prevention resources, was not associated with increased screening or counseling practices. Hence, other constructs, such as selfefficacy, needed to be assessed.

Self-efficacy significantly predicts behavioral change. ${ }^{20,21}$ The high self-efficacy demonstrated by providers in our sample indicates that given the right policies and conditions, providers could increase the frequency of screening and counselling. However, regardless of how long they have been in practice, all providers would benefit from well-designed trainings by advocacy organizations across the state.

Overall, the attitudes of health care providers demonstrate that they do not see e-cigarettes as being safer than regular cigarettes, implicating that they are not promoting e-cigarettes to their patients. Most respondents indicated that counseling youth on tobacco use should mostly be done by parents, physicians, and schoolteachers. These responses are consistent with literature on the most important protective factors for youth tobacco use. Studies clearly demonstrate the potential protectiveness provided by health care providers, schoolteachers, and parents. ${ }^{17,22}$ Therefore, existing tobacco prevention programs in Maine need to actively engage these populations and provide necessary skills and training. Parents, schoolteachers, and clinicians who provide care to middle and high school students should be included in trainings for how to screen and counsel youth on tobacco use. For schools, however, one limitation is that students would have to agree to counseling before using the resource, and parental consent may be required.

It is concerning that most health care providers' employers do not have policies on screening or counseling for youth tobacco use, despite existing recommendations. Similarly, at a time when health advocates propose screenings at every visit to a health care provider, ${ }^{22-24}$ less than one-third of Maine providers screen youth at well visits. This finding is consistent with studies from other states in which fewer health care providers screen for tobacco use. $^{25,26}$ This lack of screening is unfortunate given their potential to discourage youth tobacco use. ${ }^{15,17}$ 
Table 2. Health Care Provider Familiarity, Knowledge, and Self-Efficacy in Tobacco Use Screening by Duration of Practice

\begin{tabular}{|l|l|l|}
\hline & OR (P value $)^{*}$ & $95 \% \mathrm{Cl}$ \\
\hline Familiarity with the magnitude of cigarette use in Maine & $1.0(1.0)$ & $0.3-3.1$ \\
\hline Familiarity with the magnitude of e-cigarette use in Maine & $1.5(.5)$ & $0.5-5.4$ \\
\hline Knowledge of MaineHealth Center for Tobacco Independence & $0.7(.4)$ & $0.3-1.7$ \\
\hline Knowledge of Maine Prevention Services & $0.8(.6)$ & $0.3-1.8$ \\
\hline Knowledge of Maine Prevention Store & $0.6(.4)$ & $0.2-2.0$ \\
\hline Knowledge of Surgeon General's Advisory & $0.7(.4)$ & $0.3-1.6$ \\
\hline Knowledge of American Academy of Pediatrics statement & $1.7(.2)$ & $0.8-3.7$ \\
\hline Confident to discuss cigarette use with patients & $3.4(.002)$ & $1.6-7.4$ \\
\hline Confident to discuss e-cigarette use with patients & $1.2(.6)$ & $0.6-2.5$ \\
\hline Confident to discuss chewing tobacco with patients & $3.1(.003)$ & $1.5-6.8$ \\
\hline Confident to discuss tobacco use with parents of patients & $2.0(.07)$ & $0.9-4.0$ \\
\hline Comfort with screening patients for tobacco use & $1.2(.6)$ & $0.5-2.7$ \\
\hline
\end{tabular}

Abbreviation: OR, odds ratio; $\mathrm{Cl}$, confidence interval

${ }^{*}$ Compares providers in practice for at least 10 years to those in practice for less than 10 years.

Table 3. Responses of Maine Health Care Providers Regarding Tobacco Use in Youth

\begin{tabular}{|l|l|l|l|}
\hline Question & $\begin{array}{l}\text { E-cigarettes } \\
\text { N (\%) }\end{array}$ & $\begin{array}{l}\text { Cigarettes } \\
\text { N (\%) }\end{array}$ & $\begin{array}{l}\text { Chewing tobacco } \\
\text { N (\%) }\end{array}$ \\
\hline Use is a problem & $113(99)$ & $109(96)$ & $66(58)$ \\
\hline $\begin{array}{l}\text { Screened for use at every well-child } \\
\text { visit or annually }\end{array}$ & $44(38)$ & $49(43)$ & $33(29)$ \\
\hline $\begin{array}{l}\text { Rarely or never screened for in the } \\
\text { past year }\end{array}$ & $33(29)$ & $29(25)$ & $51(44)$ \\
\hline $\begin{array}{l}\text { Confident to discuss use with patients } \\
\text { between 11 and 18 years old }\end{array}$ & $107(94)$ & $111(97)$ & $102(89)$ \\
\hline
\end{tabular}


This practice gap in tobacco prevention demonstrates a need for more efforts by advocacy organizations and tobacco prevention programs across Maine to have health care providers understand their role in tobacco prevention efforts. The role of policy in promoting health interventions cannot be overemphasized. If there are no policies in place, it will be challenging to increase the rates of screening or counseling for youth tobacco use, or to evaluate the success of those interventions. Also, a lack of policies will lead to inconsistent results. Screening and counseling policies in clinical settings will make the prevention interventions comprehensive, assist with measuring outcomes, and aid with evaluation efforts. Having a policy in place could increase screening numbers and get providers the necessary training. ${ }^{18,27}$ Despite their high self-efficacy, health care providers need more motivation and guidance to provide needed screenings and counselling.

This study demonstrates a gap in tobacco prevention efforts in Maine. There are several tobacco prevention initiatives in the state; however, increased coordination of their efforts with health care providers will improve the translation of policy to practice. We suggest that the coordinating agency oversee the education of health care providers, parents, and schoolteachers on current tobacco prevention policies, how to screen patients, and how to provide health education to their patients, children, or students. In addition, they should also work with health administrators and health care providers to develop internal policies on tobacco screening and counseling for youth.

Our study had a few limitations. We had a small sample size, which could be due to relying on a convenience sample through professional associations. We also had a low response rate, which may be due to the dearth of health care providers in Maine. It is also known that health care providers have lower response rates to surveys. ${ }^{28}$ Due to these limitations, we are cautious in generalizing our findings to the larger population of health care providers in Maine. Furthermore, this study does not include homeless youth or youth in correctional facilities, as many of the services that we assessed are not easily accessible to these populations.

Future qualitative interviews of health care providers and administrators should be conducted to determine issues, barriers, and solutions to incorporating universal tobacco screening and counseling into their services.

\section{CONCLUSIONS}

This study identified gaps in the preventive efforts for tobacco use in Maine. Whereas cigarette smoking and other forms of tobacco use are less prevalent than e-cigarette use, the current prevalence of cigarette smoking among Maine youth is higher than the national average. Inconsistent policies on screening youth for tobacco use could contribute to a rise in e-cigarette use. We propose that agencies should develop policies to improve screening for youth tobacco use across the state of Maine and properly coordinate prevention efforts to improve health outcomes over the next few years.

\section{REFERENCES}

1. Centers for Disease Control and Prevention. Data and statistics. Smoking \& Tobacco Use. Accessed March 20, 2020. https:// www.cdc.gov/tobacco/data_statistics/index.htm?s_cid=osh-stuhome-nav-005

2. Centers for Disease Control and Prevention. Youth and tobacco use. Smoking \& Tobacco Use. Accessed March 20, 2020. https:// www.cdc.gov/tobacco/data_statistics/fact_sheets/youth_data/ tobacco_use/index.htm\#anchor_1549569386405

3. Wang TW, Gentzke AS, Creamer MR, et al. Tobacco product use and associated factors among middle and high school students United States, 2019. MMWR Surveill Summ. 2019;68(12):1-22. doi: $10.15585 / \mathrm{mmwr} . \mathrm{ss} 6812 \mathrm{a} 1$

4. Tsai J, Walton K, Coleman BN, et al. Reasons for electronic cigarette use among middle and high school students - National Youth tobacco Survey, United States, 2016. MMWR Morb Mortal Wkly Rep. 2018;67(6):196-200. doi:10.15585/mmwr. mm6706a5

5. Maine integrated youth health survey data. Maine Integrated Youth Health Survey. Accessed January 12, 2020. https://data. mainepublichealth.gov/miyhs/home

6. Maine Integrated Youth Health Survey. Snapshots. 2019 Fact Sheets. Accessed March 20, 2020. https://data. mainepublichealth.gov/miyhs/2019Snapshots

7. Maine Integrated Youth Health Survey. Detailed reports comparisons by gender, age, grade, Hispanic ethnicity, race, sexual orientation, transgender identity, public health district, and county. Maine 2019 MIYHS high school report. 2020:285.

8. Maine Integrated Youth Health Survey. Detailed reports comparisons by gender, age, grade, Hispanic ethnicity, race, sexual orientation, transgender identity, public health district, and county. Maine 2017 MIYHS high school report. 2018:169.

9. Maine Integrated Youth Health Survey. Detailed reports comparisons by gender, age, grade, Hispanic ethnicity, race, sexual orientation, transgender identity, public health district, and county. Maine 2015 MIYHS high school report.2016:111.

10. Centers for Disease Control and Prevention. Map of current cigarette use among youth. State Tobacco Activities Tracking and Evaluation (STATE) System. Accessed January 14, 2020. https://www.cdc.gov/statesystem/cigaretteuseyouth.html 
11. Centers for Disease Control and Prevention. 2014 surgeon general's report: The health consequences of smoking-50 years of progress. Smoking \& Tobacco Use. Accessed January 2, 2020. https://www.cdc.gov/tobacco/data_statistics/sgr/50thanniversary/index.htm

12. Manoj Sharma M, Haider T. Hookah smoking in US adolescents: Implications for research and practice. $J$ Alcohol Drug Educ. 2016;60(2):3. https://search.proquest.com/ docview/1826099229?pq-origsite $=$ gscholar\&fromopenview $=\operatorname{tr}$ ue

13. Centers for Disease Control and Prevention. Health effects. Smoking \& tobacco use. Accessed February 1, 2020. https:// www.cdc.gov/tobacco/basic_information/health_effects/index. $\mathrm{htm}$

14. Committee on Substance Abuse, Levy SJL, Kokotailo PK. Substance use screening, brief intervention, and referral to treatment for pediatricians. Pediatrics. 2011;128(5):e13301340. doi:10.1542/peds.2011-1754

15. US Preventive Services Task Force. Tobacco use in children and adolescents: Primary care interventions. Final recommendation statement. Updated August 15, 2013. Accessed January 9, 2020. https://www.uspreventiveservicestaskforce.org/Page/ Document/RecommendationStatementFinal/tobacco-use-inchildren-and-adolescents-primary-care-interventions

16. Patnode CD, O'Connor E, Whitlock EP, Perdue LA, Soh C, Hollis J. Primary care-relevant interventions for tobacco use prevention and cessation in children and adolescents: a systematic evidence review for the US Preventive Services Task Force. Ann Intern Med. 2013;158(4):253-260. doi:10.7326/0003-4819-1584-201302190-00580

17. Balogun T, Soma T, Corvino T, O'Brien L, Plimpton R. Prevalence and correlates of cigarette smoking among high school students in Maine. Poster presented at: Maine Public Health Association Conference; October 16, 2018; Augusta, $\mathrm{ME}]$.

18. Pbert L, Farber H, Horn K, et al. State-of-the-art office-based interventions to eliminate youth tobacco use: The past decade. Pediatrics. 2015;135(4):734-747. doi: https://doi.org/10.1542/ peds.2014-2037
19. Stata 15. Version 15. Stata Corp; 2017. College Station, TX http://www.stata.com/

20. Champion VL, Skinner CS. The health belief model. In: Glanz K, Rimer BK, Viswanath K, eds. Health Behavior and Health Education: Theory, Research, and Practice. 4th ed. John Wiley \& Sons; 2008:45-52.

21. Ozer EM, Adams SH, Gardner LR, Mailloux DE, Wibbelsman CJ, Irwin Jr CE. Provider self-efficacy and the screening of adolescents for risky health behaviors. $J$ Adolesc Health. 2004;35(2):101-107. doi:10.1016/j.jadohealth.2003.09.016

22. Balogun T, Troisi C, Swartz MD, Lloyd L, Beyda R. Factors associated with knowledge of where to access health care among youth in juvenile detention: A mixed methods study [published online ahead of print March 19, 2019]. Int J Adolesc Med Health. 2019. doi:10.1515/ijamh-2018-0128

23. Pepper JK, McRee A-L, Gilkey MB. Healthcare providers' beliefs and attitudes about electronic cigarettes and preventive counseling for adolescent patients. $J$ Adolesc Health. 2014;54(6):678-683. doi:https://doi.org/10.1016/j. jadohealth.2013.10.001

24. American Academy of Pediatric Dentistry. Policy on tobacco use. Accessed February 20, 2020.https://www.aapd.org/ research/oral-health-policies--recommendations/tobacco-use/

25. Schauer GL, Agaku IT, King BA, Malarcher AM. Health care provider advice for adolescent tobacco use: results from the 2011 National Youth Tobacco Survey. Pediatrics. 2014;134(3):446455. doi:10.1542/peds.2014-0458

26. Dai $\mathrm{H}$, Clements $\mathrm{M}$. Trends in healthcare provider advice on youth tobacco use, 2011-2015. Am J Prev Med. 2018;55(2):222230. doi:10.1016/j.amepre.2018.04.015

27. Barrington-Trimis JL, Kong G, Leventhal AM, et al. E-cigarette use and subsequent smoking frequency among adolescents. Pediatrics. 2018;142(6): e20180486. doi:10.1542/peds.20180486

28. Cho YI, Johnson TP, VanGeest JB. Enhancing surveys of health care professionals: a meta-analysis of techniques to improve response. Eval Health Prof. 2013;36(3):382-407. doi:10.1177/0163278713496425 